\title{
Two invasive mosquito species, Aedes albopictus and Aedes japonicus japonicus, trapped in south-west Germany, July to August 2011
}

D Werner (doreen.werner@zalf.de)1', M Kronefeld², F Schaffner³, H Kampen²

1. Leibniz-Centre for Agricultural Landscape Research, Müncheberg, Germany

2. Friedrich-Loeffler-Institut, Federal Research Institute for Animal Health, Greifswald - Insel Riems, Germany

3. Institute of Parasitology, University of Zurich, Zurich, Switzerland

Werner D, Kronefeld M, Schaffner F, Kampen H. Two invasive mosquito species, Aedes albopictus and Aedes japonicus japonicus, trapped in south-west Germany, July to August 2011

Euro Surveill. 2012;17(4):pii=20067. Available online: http://www.eurosurveillance.org/ViewArticle.aspx?Articleld=20067

Article published on 26 January 2012

Adult females of two invasive species, Aedes albopictus and Aedes japonicus japonicus, were collected for the first time in July and August 2011 in Germany. Previously, only immature stages of these species had been found in the country. Repeated detection of these species reveals the Upper Rhine Valley in southwest Germany to be a particularly sensitive region for the introduction and establishment of exotic mosquito species that needs careful observation.

As part of nationwide mosquito monitoring activities, two invasive mosquito species, Aedes albopictus and Ae. japonicus japonicus, were trapped in the Upper Rhine Valley in south-west Germany (federal state of Baden-Württemberg), in the summer of 2011. Neither of these culicid species had been previously collected in Germany as adult specimens.

Various exotic mosquito species such as Ae. albopictus, Ae. j. japonicus, Ae. atropalpus, Ae. koreicus and $A e$. aegypti have recently invaded Europe [1]. In a few instances, eradication has been possible but Ae. albopictus and Ae. j. japonicus have become established and continue to spread $[2,3]$. Autochthonous human cases of chikungunya in northern Italy and southern France and of dengue in southern France and Croatia have been attributed to the presence of the vector Ae. albopictus [4-6]. This, together with the demonstration of several pathogenic viruses in fieldcollected mosquitoes in Germany [7-9], prompted the German authorities to initiate nationwide mosquito monitoring activities in 2011.

\section{Background}

Ae. albopictus is a most efficient vector of numerous arboviruses [10]. After its introduction into Italy in the late 1980s, it is now widely distributed in the Mediterranean region and continues to spread [11]. While this species actively moves within short distances, the most important mode of long-distance dispersal is passive transportation by vehicles [1]. Although $A e$. j. japonicus has been found carrying West Nile virus in the field and its vector competence has been demonstrated in the laboratory for several viruses, the role of this species in the natural transmission of pathogens is unclear [1].

\section{Trapping strategy}

To search for invasive mosquito species, BG-Sentinel traps (Biogents, Germany) were set up in southern Germany at various possible portals of entry for exotic mosquitoes, i.e. along public transportation routes close to borders with neighbouring countries. The traps were operated permanently from the beginning of July to the end of August 2011, with a sample collection interval of seven days. During the whole season, the traps were equipped with BG-Lure (Biogents), a proven attractant for several exotic mosquito species. To increase the catching efficacy, carbon dioxide $\left(\mathrm{CO}_{2}\right)$ was added as an additional attractant for the last 24 hours of the weekly collection period. It was supplied from gas bottles at a rate of approximately $20 \mathrm{~g} / \mathrm{h}$ and released through a nozzle $20 \mathrm{~cm}$ above the trap. Collected mosquitoes were morphologically identified using the identification keys of Schaffner et al. [12] and Becker et al. [13]. Genetic confirmation was performed by cytochrome coxidase subunit I (COI) barcode region PCR amplification [14] and DNA sequencing following standard protocols. Sequence analysis was carried out using the COI species identification tool of the Barcode of Life Data Systems [15].

\section{Mosquitoes trapped}

A total of 10 female specimens of Ae. j. japonicus and one single female specimen of Ae. albopictus were identified in a trap operated behind a rest area on the A5 motorway entering Germany from Switzerland (N $47^{\circ} 36^{\prime}$ '03.5”, E $07^{\circ} 36^{\prime}$ 18.7') (Figure). The Ae. j. japonicus females were collected from mid-July to the end of 
August, while the Ae. albopictus female was trapped in late July (Table).

In a second trap, set up in a cemetery in Freiburg (Figure), close to a truck-railway transshipment station (N 48 0o' 39.7”, E $07^{\circ}$ 50' 27.8'”), a female Culiseta longiareolata was detected in mid-August (Table).

In addition to the three mosquito species mentioned, several female specimens of indigenous species were collected in the two traps, in particular Culex hortensis at the site in Weil am Rhein and $C x$. pipiens or

\section{FIGURE}

Trap location (1) where two culicid mosquito species (Aedes albopictus and Ae. japonicus japonicus) were collected, Baden-Württemberg, Germany, July-August 2011

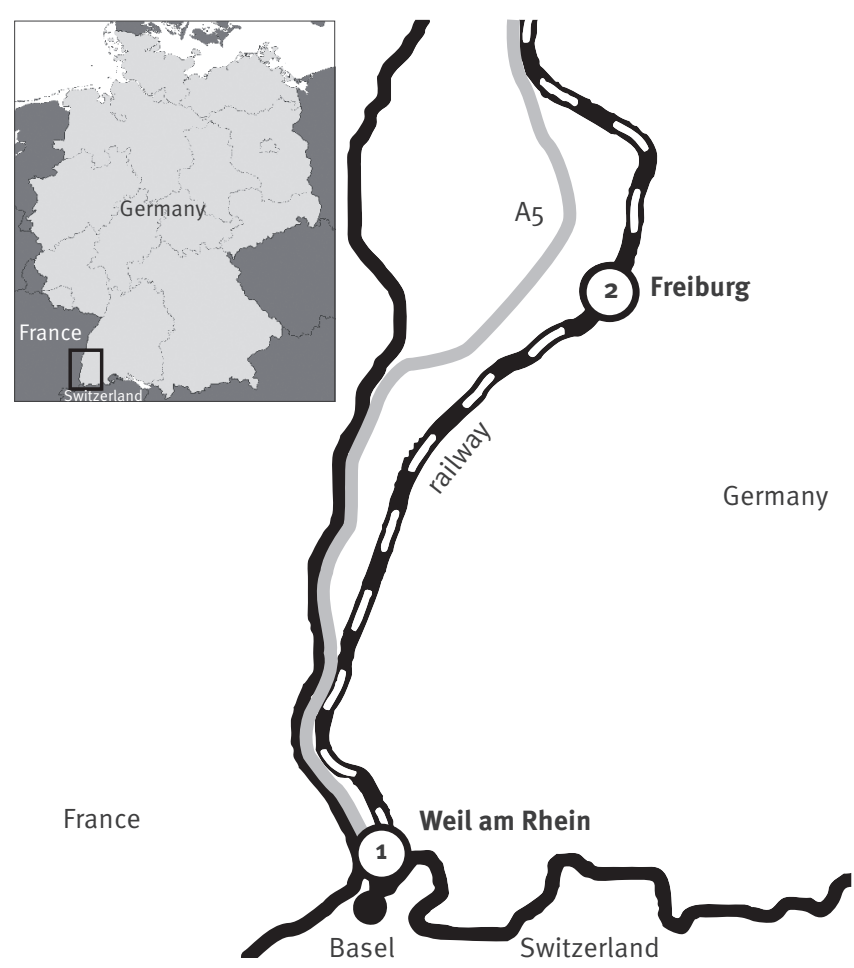

A second trap, in Freiburg, is indicated (2), where a female Culiseta longiareolata was detected.
Cx. torrentium at the site in Freiburg (Table). No male specimens of any mosquito species were trapped.

\section{Implications of the findings}

After the earlier finding of five eggs of Ae. albopictus in an ovitrap in September 2007 [16] and the finding of numerous preimaginal stages of $A e . j$. japonicus in 2008, 2009 and 2010 [2,17,18], the females described in this study are the first adult mosquitoes of these species trapped in Germany. For Ae. albopictus, it is only the second time that this species has been observed in the country. Although monitoring of adult mosquitoes should not replace the monitoring of immature stages, it has the advantage that breeding sites need not be searched for and arduously examined. Also, species identification in adults is much easier and quicker, so that response times for control can be accelerated. The finding of adults may indicate directions of dispersal and, if introduction can be excluded, show that environmental conditions are adequate to complete the developmental cycle.

As the most important mode of long-distance dispersal of $A e$. albopictus is passive transportation by vehicles, the A5 motorway, entering Germany from Switzerland, represents one of the most likely portals of entry for the introduction of this species by ground vehicles from southern Europe. Indeed, the only demonstration of Ae. albopictus stages in Germany before this study, namely five eggs in an ovitrap in 2007 , was associated with a parking area on this motorway close to the Swiss border [16].

After various reports from other central European countries, Ae. j. japonicus was first detected in Germany in the German-Swiss border zone during a Swiss study in 2008 [2]. Due to its demonstrated wide distribution in the sampled region, this species is thought to have been present unnoticed for several years. However, it could not be found in Weil am Rhein and the adjacent municipalities at that time. It was only in 2009 that monitoring in south-western Germany revealed the widespread occurrence of $A e . j$. japonicus immature stages in Germany, including in the Weil am Rhein

TABLE

Adult (female) mosquitoes trapped at two sites, Baden-Württemberg, Germany, July-August 2011

\begin{tabular}{|c|c|c|c|c|c|c|c|c|c|c|c|c|c|c|c|c|}
\hline \multirow{4}{*}{ Mosquito species } & \multicolumn{16}{|c|}{ Number of adult mosquites trapped } \\
\hline & \multicolumn{8}{|c|}{ Trap site 1 (Weil am Rhein) } & \multicolumn{8}{|c|}{ Trap site 2 (Freiburg) } \\
\hline & \multicolumn{16}{|c|}{ Calendar week July-August 2011} \\
\hline & 27 & 28 & 29 & 30 & 31 & 32 & 33 & 34 & 27 & 28 & 29 & 30 & 31 & 32 & 33 & 34 \\
\hline Aedes albopictus & - & - & - & 1 & - & - & - & - & - & - & - & - & - & - & - & - \\
\hline Aedes japonicus japonicus & - & 2 & 3 & 3 & - & 1 & - & 1 & - & - & - & - & - & - & - & - \\
\hline Culiseta annulata & - & - & 1 & - & - & - & - & - & - & - & - & - & - & - & - & - \\
\hline Culiseta longiareolata & - & - & - & - & - & - & - & - & - & - & - & - & - & - & 1 & - \\
\hline Culex hortensis & 4 & 1 & - & 3 & 2 & - & 1 & 5 & - & - & - & - & - & - & - & - \\
\hline Culex pipiens and/or Culex torrentium & - & - & - & 1 & - & 1 & 2 & 1 & 5 & 4 & 6 & 4 & 2 & 5 & 4 & 4 \\
\hline
\end{tabular}


region [17]. Thus, our new data from 2011 confirm the persistence of this species in southern Germany.

Before summer 2011, Cs. longiareolata - a thermophilic mosquito species that in Europe is endemic to the Mediterranean - had never been collected in Germany. Around the same time as our study, larvae and pupae of Cs. longiareolata were found in another area of south-western Germany [19], some $140 \mathrm{~km}$ north of our collection site and also adjacent to the A5 motorway. In our study, the adult was caught near a truck-railway transshipment station, a destination of numerous trucks from southern Europe. The vector capacity of this bird-biting species is unknown.

In our study, the mosquito species were caught using suction traps for adults. As the traps were operated for two months only and the climatic conditions in southern Germany in 2011 were relatively bad for mosquitoes, the trapping of the three species is probably due to a combination of a highly sensitive trapping system and the selection of suitable trap positions. The BG-Sentinel trap has been shown in a variety of studies to be superior to other traps for collecting some exotic Aedes species, and in combination with $\mathrm{CO}_{2}$, it is at least as efficient as other $\mathrm{CO}_{2}$ traps for the collection of other culicid species [e.g. 20]. Due to our particular collection regimen, however, the contribution of $\mathrm{CO}_{2}$ to the collection success is not clear. In addition to the trap efficacy, the selection of the trap position is an important factor influencing the collection result. We carefully inspected possible sites for the release of imported mosquitoes from vehicles entering Germany and placed the traps within flight distance (a few hundred metres) at sites on non-public premises protected from wind, sun and rain.

In summary, our study provides evidence of a second introduction of $A$ e. albopictus into Germany and the persistence of $A e$. j. japonicus in south-western Germany. Our findings confirm that the German Upper Rhine Valley is a suitable area for the introduction and establishment of invasive species [3], further highlighted by our finding of an adult Cs. longiareolata. It is characterised by a very mild climate likely to offer suitable climatic conditions for the establishment of thermophilic exotic mosquito species. Our results call for further search for mosquito adults and immature stages, particularly of Ae. albopictus, in 2012 along the major traffic axes in south-western Germany through intensified monitoring. Should additional adults or even immature stages of Ae. albopictus be found, control measures such as insecticiding, reduction of potential breeding sites and public health education should immediately be implemented. The further spread of $A e$. j. japonicus in southern Germany can probably only be prevented by extensive public education on the developmental demands of this species and appeals to the public to avoid producing artificial man-made breeding sites.
Acknowledgments

This work was financially supported by the German Federal Ministry of Food, Agriculture and Consumer Protection (BMELV) through the Federal Office for Agriculture and Food (BLE), grant number 2810HSo22, and by the Robert Koch Institute, grant number 1362/1-982.

We are grateful to Brigitte Dannenfeld for excellent technical assistance in the laboratory and numerous persons taking care of our mosquito traps.

\section{References}

1. Medlock J, Hansford KM, Schaffner F, Versteirt V, Hendrickx G, Zeller $\mathrm{H}$, et al. A review of the invasive mosquitoes in Europe: ecology, public health risks, and control options. Vector-Borne Zoon Dis. 2012. Forthcoming.

2. Schaffner F, Kaufmann C, Hegglin D, Mathis A. The invasive mosquito Aedes japonicus in Central Europe. Med Vet Entomol. 2009;23(4):448-51.

3. European Centre for Disease Prevention and Control (ECDC). Development of Aedes albopictus risk maps. ECDC Technical Report. Stockholm: ECDC; 2009. Available from: http:// ecdc.europa.eu/en/publications/Publications/0905_TER Development_of_Aedes_Albopictus_Risk_Maps.pdf,.

4. Rezza G, Nicoletti L, Angelini R, Romi R, Finarelli AC, Panning $M$, et al. Infection with chikungunya virus in Italy: an outbreak in a temperate region. Lancet. 2007;370(9602):1840-6.

5. Gould EA, Gallian P, De Lamballerie X, Charrel RN. First cases of autochthonous dengue fever and chikungunya fever in France: from bad dream to reality! Clin Microbiol Infect. 2010;16(12):1702-4.

6. Gjenero-Margan I, Aleraj B, Krajcar D, Lesnikar V, Klobučar A, Pem-Novosel I, et al. Autochthonous dengue fever in Croatia, August-September 2010. Euro Surveill. 2011;16(9): pii=19805. Available from: http://www.eurosurveillance.org/ViewArticle. aspx?Articleld $=19805$

7. Jöst H, Bialonski A, Storch V, Günther S, Becker N, SchmidtChanasit J. Isolation and phylogenetic analysis of Sindbis viruses from mosquitoes in Germany. J Clin Microbiol. 2010;48(5):1900-3.

8. Jöst H, Bialonski A, Maus D, Sambri V, Eiden M, Groschup MH, et al. Isolation of Usutu virus in Germany. Am J Trop Med Hyg. 2011;85(3):551-3.

9. Jöst H, Bialonski A, Schmetz C, Günther S, Becker N, SchmidtChanasit J. Isolation and phylogenetic analysis of Batai virus, Germany. Am J Trop Med Hyg. 2011;84(2):241-3.

10. Gratz N. Critical review of the vector status of Aedes albopictus. Med Vet Entomol. 2004;18(3):215-27.

11. Romi R, Majori G. An overview of the lesson learned in almost 20 years of fight against the "tiger" mosquito. Parassitologia. 2008;50(1-2):117-9.

12. Schaffner F, Angel G, Geoffroy B, Hervy JP, Rhaiem A, Brunhes J. The mosquitoes of Europe. An identification and training programme [CD-ROM]. Montpellier: IRD Éditions \& EID Méditerrannée; 2001.

13. Becker N, Petrić D, Zgomba M, Boase C, Madon M, Dahl C, et al. Mosquitoes and their control. 2nd ed. Heidelberg: Springer; 2010.

14. Folmer O, Black M, Hoeh W, Lutz R, Vrijenhoek R. DNA primers for amplification of mitochondrial cytochrome $c$ oxidase subunit I from diverse metazoan invertebrates. Mol Mar Biol Biotechnol. 1994;3(5):294-9.

15. Ratnasingham S, Hebert PD. bold: The Barcode of Life Data System (www.barcodinglife.org). Mol Ecol Notes. 2007;7(3):355-4.

16. Pluskota B, Storch V, Braunbeck T, Beck M, Becker N. First record of Stegomyia albopicta (Skuse) (Diptera: Culicidae) in Germany. Eur Mosq Bull. 2008;26:1-5.

17. Becker N, Huber K, Pluskota B, Kaiser A. Ochlerotatus japonicus japonicus - a newly established neozoan in Germany and a revised list of the German mosquito fauna. Eur Mosq Bull. 2011;29:88-102.

18. Schneider K. Breeding of Ochlerotatus japonicus japonicus 80 $\mathrm{km}$ north of its known range in southern Germany. Eur Mosq Bull. 2011;29:129-32.

19. Becker N, Hoffmann D. First record of Culiseta longiareolata (Marcquart) for Germany. Eur Mosq Bull. 2011;29:143-50. 
20. Meeraus WH, Armistead JS, Aria JR. Field comparison of novel

and gold standard traps for collecting Aedes albopictus in northern Virginia. J Am Mosq Contr Assoc. 2008;24(2):244-8. 